\title{
Effect of Nutrient Sources on the Alginate Accumulation in the Culture Liquid of Azotobacter vinelandii D-05 and Obtaining Biocomposite Materials
}

\author{
Victor Vasilevich Revin ${ }^{1}$, Elena Gennadievna Kostina ${ }^{1}$, Nadezhda Victorovna Revina ${ }^{1}$, \\ Vitalina Victorovna Shutova ${ }^{1 *}$. \\ ${ }^{I}$ Ogarev Mordovia State University - Biotechnology and Biology, Saransk, Russian Federation.
}

\begin{abstract}
Using the classic biotechnological methods, the dependence of A. vinelandii D-05 culture alginate production from the media carbon and nitrogen content was investigated. The maximal alginate production was observed during cultivation bacterium in the medium with 2 to $4 \%$ of sucrose, but the maximal growth was found in the medium with $4 \%$ glucose. It was found that for the alginate production the optimal nitrogen contents could take from $0.05 \%$ yeast extract (carbon: nitrogen ratio 168:1). For the first time we demonstrated possibility the A. vinelandii growth during the cultivation in a medium with molasses (a by-product of sugar production) and the significant polysaccharide production $(16.6 \mathrm{~g} / \mathrm{l})$ was obtained. It was established, that A. vinelandii culture broth could be used as a biological binder for obtaining the biocomposite materials.
\end{abstract}

Key words: Azotobacter vinelandii; alginate; nutrient medium; carbon: nitrogen ratio; biocomposite.

\footnotetext{
*Author for correspondence: vshutova@yandex.ru
} 


\section{INTRODUCTION}

Currently, the microbial polysaccharides are widely used in the various fields of the human activity, such as medicinal ${ }^{1}$, pharmaceutical $^{2}$, food, textile and chemical industries, oil production, and hydrometallurgy, to obtain the composite materials ${ }^{3,4}$. Despite advances in biotechnology, the number of commercially available microbial polysaccharides is extremely limited. The problems of determining both the new microbial polysaccharides producers and the efficient preparation methods for the various products remain to be resolved ${ }^{5,6}$. The optimization of the culture medium provides the key to the development of the modern methods for preparations of the microbial polysaccharides.

The alginates represent a family of the unbranched copolymers of $\beta$-D-mannuronic and $\alpha$-L-guluronic acids, 1-4-linked and having differing composition and structure ${ }^{7}$. They are widely used in a medicine, in the food industry as gelling and the stabilizing agents, in the agriculture, in bio sorption of the metals, and in a number of areas ${ }^{8,9,10,11}$. A. vinelandii bacteria are considered as promising producers due to their ability to synthesize the alginates consisting of homopolymer blocks of the mannuronic and the guluronic acid as alternating units in the mixed blocks ${ }^{7}$.

It is known that the polysaccharides possess good adhesive properties. The adhesives (binder), which include of the microbial origin polysaccharides (levan from Azotobacter, dextran from Leuconostoc) can be used to improve the environmental safety of wood composite materials instead of toxic synthetic resins and adhesives. The producers of these polysaccharides are Leuconostoc, Azotobacter, Gluconoacetobacter bacteria, grown on waste from beet sugar, starch, dairy and fermentation industries. In the process of bacterial growth, we found the accumulation of the high polymeric compounds - polysaccharides. They can be used as the main component in a bio glue and as a binder for the production of wood composites. Using the compression, we obtained biocomposite material based on the lignocellulosic materials and the levan and dextran containing culture broth ${ }^{12,13,14,15}$.

The general idea of the current study was to optimize the media composition of the carbon and nitrogen nutrition for Azotobacter vinelandii D-05 growth and alginate production and to investigate the possibility of alginate-containing culture broth as a biological binder for biocomposites.

\section{MATERIALS AND METHODS}

\section{Strain and the culture media}

The object of this study was bacterium A. vinelandii D-05 obtained from the VCIM. The culture was maintained on Ashby agar medium of the following composition $(\mathrm{g} / \mathrm{l})$ : mannitol - 20, $\mathrm{K}_{2} \mathrm{HPO}_{4}-0.2, \mathrm{NaCl}-0.2, \mathrm{~K}_{2} \mathrm{SO}_{4}-0.1, \mathrm{FeSO}_{4}-0.1, \mathrm{CaCO}_{3}-5$, agaragar -20 , pH $6.8-7.2$. Bacteria were grown on the agar medium in a thermostat at $28 \pm 1^{\circ} \mathrm{C}$ for 5 days.

The various carbon compounds the bacterium consumption in culture was investigated using Hiss color media of the following composition, g / l: carbon source (carbohydrate or alcohol) - 10; peptone - 5.0; $\mathrm{K}_{2} \mathrm{HPO}_{4}-1.0$; bromothymol blue indicator $-2 \mathrm{ml}$ of $1.6 \%$ alcohol solution per 1 liter of water.

In this study the carbon sources utilized were sucrose, fructose, xylose, glucose, arabinose, dulcitol, inositol, mannitol, lactose, and rhamnose. A background medium without the carbon source as a control was used.

The prepared medium was dispensed $(9 \mathrm{ml})$ into tubes with the floats and sterilized at $0.5 \mathrm{~atm}$ during $20 \mathrm{~min}$. The medium was inoculated with the microbial cell suspensions $(0.2 \mathrm{ml})$ and was incubated at $30^{\circ} \mathrm{C}$ during 4 days. After incubation, the 
Nutrient Sources and Alginate Accumulation

presence or absence of microbial growth in the carbon source medium was controlled by the medium revealing turbidity and precipitate formation. In addition, the indicators light intensities changes during the formation of acidic metabolic products and $\mathrm{pH}$ changes (at pH 7.6, the bromothymol blue indicator is blue, and at $\mathrm{pH} 6.0$, it is yellow). In the $\mathrm{A}$. vinelandii growth and alginate production experiments, we used modified M22 medium ${ }^{16}$ of the following composition (g/l): $\mathrm{KH}_{2} \mathrm{PO}_{4}-0.011 ; \mathrm{Na}_{2} \mathrm{HPO}_{4}-0,189$; $\mathrm{MgSO}_{4} \quad 7 \mathrm{H}_{2} \mathrm{O}-0,2 ; \mathrm{CaSO}_{4} 2 \mathrm{H}_{2} \mathrm{O}-0,02 ; \mathrm{FeSO}_{4} 7 \mathrm{H}_{2} \mathrm{O}-0,006 ; \mathrm{MoO}_{3}-0,00005 ;$ $\mathrm{NaCl}-0.01 ; \mathrm{NaHCO}_{3}-0.05, \mathrm{pH} 7.8$.

Carbon sources (sucrose, glucose, lactose, and mannitol) were added at concentrations $1.5 ; 2 ; 4 \%$. As the nitrogen source, yeast extract was added to the medium $(0.5 \%)$.

The nitrogen source $\left(\mathrm{NaNO}_{3}\right.$, yeast extract, peptone, $\left.\left(\mathrm{NH}_{4}\right)_{2} \mathrm{SO}_{4}\right)(0.03,0.04,0.05$, and $0.06 \%$ ) effects on the growth and exopolysaccharide production (EPS) was investigated using the modified M22 medium with $2 \%$ sucrose.

Cultivation was also carried out on molasses medium ( $4 \%$ sucrose) of the following composition (g/l): molasses - 100 (40\% sucrose), pH 6.8 .

\section{Inoculum preparation and the cultivation conditions}

A two-day culture was used as an inoculum. The inoculum $(5 \mathrm{~mL})$ with the optical density at OD600 - 0.05 was added to flasks. Optical density of the culture broth using the UV-3600 -spectral-photometer (Shimadzu, Japan) for registration the light absorbance at $600 \mathrm{~nm}$ was measured. Samples were diluted if absorbance was above 0.05 . The cultivation for 5 days at $28^{\circ} \mathrm{C}$ on a shaking incubator (ES-20/60 (Biosan, Latvia) (220 rev/min) was carried out.

\section{Analytical methods}

The biomass and the culture broth (CB) polysaccharide contents after drying and weighing were determined. After the biomass fermentation, $10 \mathrm{~mL}$ culture broth was centrifuged at $8000 \mathrm{rpm}$ for $30 \mathrm{~min}$ (Centrifuge CLn-16, Changsha Xiangzhi Centrifuge Instrument, China) and then the pellet for 24 hours at $100^{\circ} \mathrm{C}$ was dried. The cdw $(\mathrm{g} / \mathrm{L})$ is the coefficient was calculated as the weight difference. Alginate precipitation from the culture broth was performed by twice its volume of isopropanol ${ }^{17}$. The alginate was precipitated from the supernatant separated from the cells with 2 volumes of $96 \%$ cold isopropanol and separated by centrifugation at 2,500 $\times \mathrm{g}$ for $15 \mathrm{~min}$. After being dissolved in MilliQ water, the polymer was precipitated. This process was repeated two more times, and the polymer was finally dried.

\section{Binder and biocomposite materials obtaining}

To obtain the binder, we used M22 medium supplemented with $20 \mathrm{~g} / \mathrm{l}$ sucrose and $0.50 \mathrm{~g} / \mathrm{l}$ yeast extract. The cultivation was carried out for 4 days. The procedure of the press-mass preparing included next: the pine sawdust was mixed with a binder by extrusion method; the sawdust (100 g) was mixed with $100 \mathrm{ml}$ A. vinelandii D-05 culture broth and dried at $60^{\circ} \mathrm{C}$ to a 6 to $8 \%$ moisture content; as a hydrophobizator, $1 \%$ of paraffin was added. The substrates $(100 \mathrm{~g})$ were placed into a mold $\left(5^{\times} 15 \mathrm{~cm}\right)$ and subjected to compression in a molding hydraulic press GT-7014-H (Gotech, Taiwan) at $180^{\circ} \mathrm{C}$, pressure $26 \mathrm{MPa}$ during $20 \mathrm{~min}$, and followed by cooling. The obtained boards density was determined using automatic densitometer of high resolution H-200L (Gotech, Taiwan). According to Russian Federation standard, flexural strength was restarted using a tensile-testing machine UAI-7000 unit (Gotech, Taiwan). The values of water absorption and swelling were measured compare the samples weight and thickness after water immersion. 
The results were subjected to statistical analysis using Microsoft Excel 2007 programs $(n=10-15)$.

\section{RESULTS AND DISCUSSION}

To test the ability of A. vinelandii D-05 to utilize the carbohydrates and alcohols, in our experiments the cultivation was on Hiss colored media with the $\mathrm{pH}$-depended light indicator, (bromothymol blue), which changes the medium color from yellow to blue in the interval from $\mathrm{pH} 6.0$ - 7.6. It was found, that from the ten carbon sources tested, only the sucrose, glucose, lactose and the mannitol were changed $\mathrm{pH}$ because the of carbon sources was includes into the microorganism metabolism. One other side, the slight light change of $\mathrm{pH}$ indicator was observed during the bacterium cultivation in media with arabinose, fructose and rhamnose.

To study the effect of carbon sources on the growth of $A$. vinelandii, the cultivation was carried out on the media containing different mannitol concentrations (of 1.5 to $4 \%$ ). It was shown that in all mannitol concentrations, the growth of $A$. vinelandii and the biomass increase was observed at up to three days of the cultivation, followed by it decrease, perhaps, the initiation of the cell lytic processes. At the bacterium growth in the $1.50 \%$ mannitol containing media (Fig. $1 \mathrm{~A}$ ), the biomass production was insignificant. Increasing the carbon source concentration resulted in intensification of the growth processes. The best growth was observed at mannitol concentration $4 \%$ $(5.6 \mathrm{~g} / \mathrm{l})$.

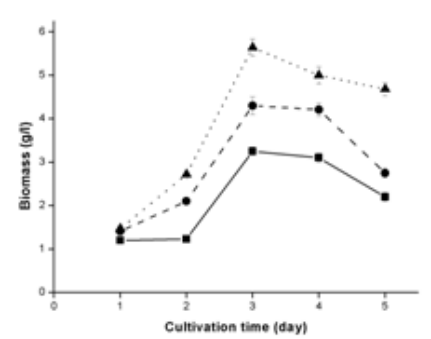

A

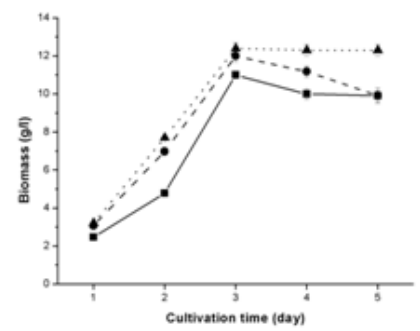

$\mathrm{C}$

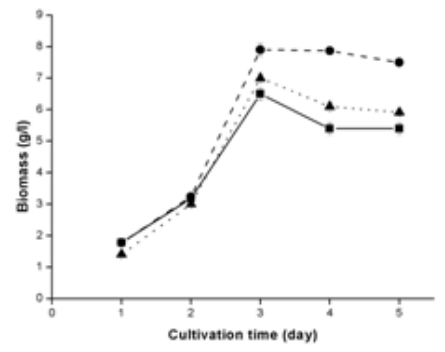

B

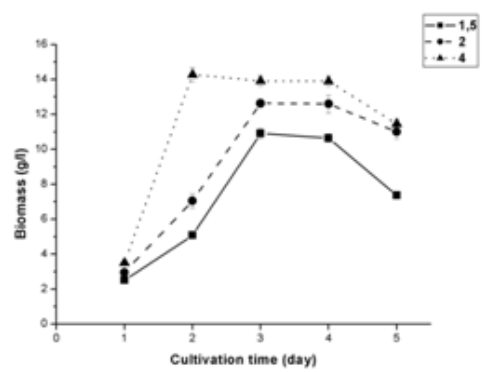

$\mathrm{D}$

Fig.1. Influence of carbon source concentration in the medium on A. vinelandii growth: A - mannitol; B - lactose; C - sucrose; D - glucose.

Key: Concentration (\%): $1.5(\boldsymbol{\bullet}), 2(\bullet), 4(\mathbf{\Delta})$

Using the lactose as a carbon source, similarly to mannitol, A. vinelandii grew up to 3 days was found (Fig. $1 \mathrm{~B}$ ). The lowest of the biomass contents was at $1.5 \%$ lactose contained media, the $2 \%$ lactose stimulated the biomass production by $18 \%(7.9 \mathrm{~g} / \mathrm{L})$ but at $4 \%$ lactose contained media the bacterium growth decreased, as in the data previously reported ${ }^{18}$. 
Nutrient Sources and Alginate Accumulation

The substitution of the mannitol and lactose for sucrose led to improve $A$. vinelandii biomass level and the maximum biomass content of (12 g / l) was observed during cultivation at $2-4 \%$ sucrose contained media (Fig. $1 \mathrm{C}$ ).

The maximal of the A. vinelandii $\mathrm{D}$ - 05 culture growth was observed in glucose contained media. It was shown that the changes from 1.5 to $4 \%$ glucose concentration in the culture medium led to an increase of the biomass content and in $4 \%$ glucose contained media, the maximum biomass was observed as early as the second day (Figure 1 D).

It was found, that the existence of the carbon source in the culture medium changed not only the bacterium growth but also the synthesis of microbial metabolites including extracellular polysaccharides (EPS). (Fig. 2).

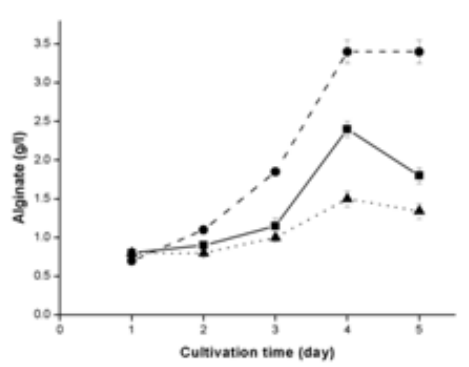

A

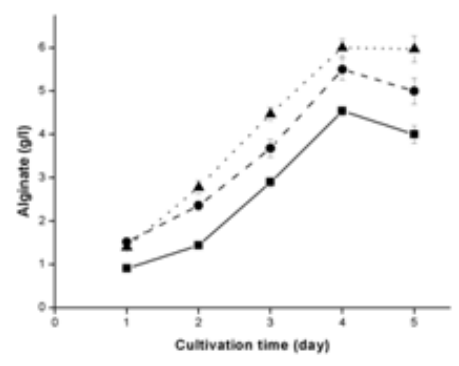

C

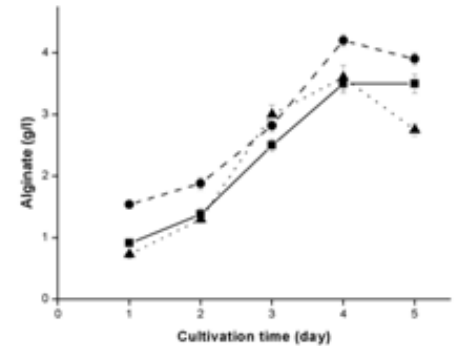

B

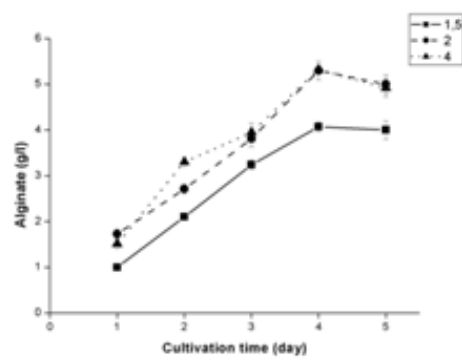

D

Fig. 2. Influence of carbon source concentration on the exopolysaccharide accumulation by Azotobacter vinelandii: A - mannitol; B - lactose; C - sucrose; D - glucose.

Key: Concentration (\%): $1.5(\boldsymbol{\bullet}), 2(\bullet), 4(\mathbf{\Delta})$

In all experiments the maximum EPS content in the culture broth (CB) was observed during four days (stationary phase of growth) and subsequently slightly decreased or remained at the control level. It is important that during cultivation the bacterium in mannitol contained media, the highest the alginate production was observed at $2 \%$ mannitol - and $3.4 \mathrm{~g} / \mathrm{l}$ (Fig. $2 \mathrm{~A}$ ), but at $4 \%$ the polysaccharide synthesis was blocked whereas the A. vinelandii biomass content was maximal (see Fig. 1 A).

During cultivation the bacterium with lactose the alginate biosynthesis was increased (in comparison with mannitol) (Fig. 2 B). The maximal of EPS contents was observed in $2 \%$ lactose, contained media, possible, directly depend on the biomass level.

As in the case of mannitol, increasing the lactose content in a medium to $4 \%$ inhibited the alginate biosynthesis and it fits the data that the concentrations more $1 \%$ lactose decrease the biosynthesis of alginate by A. vinelandii MTCC $2459^{18}$. 
The optimal sucrose concentration for the culture growth and alginate biosynthesis (Fig. $2 \mathrm{C}$ ) was $2 \%(5.5 \mathrm{~g} / \mathrm{l}$ on the 4 th day) and it increase to $4 \%$ did not lead to significant the polysaccharide biosynthesis.

It should be noted that the alginate production at $A$. vinelandii cultivation on a sucrose contained media was more than in medium with either mannitol or lactose. It was known ${ }^{18}$, the sucrose was also an optimal carbon source for A. vinelandii MTCC 2459. It is known that for a number of various Azotobacter species and strains, cultivation at $2 \%$ glucose is one of the best substrates for alginate production ${ }^{17,19,20}$.

However, in our experiments, the change of sucrose by glucose did not increase EPS production in the A. vinelandii D - 05 culture broth (Figure $2 \mathrm{D}$ ). For example, the alginate content in the experiment $1.5 \%$ glucose contained media was lower than at higher concentrations $(2-4 \%)$.

In these experiments were found that during the bacteria $A$. vinelandii $\mathrm{D}-05$ cultivation it is possible using the different carbon sources for growth and alginate biosynthesis: mono-, disaccharides and polyhydric alcohol mannitol.

It is know, that the basic components of any culture medium are carbon and nitrogen compounds. Exactly these compounds and their ratios determine the specificity of the culture media ${ }^{21}$. Therefore, we investigated the effect of various concentrations of the nitrogen sources on the growth and the alginate production at $4 \%$ sucrose contained media. For this purpose, $\mathrm{NaNO}_{3}$, and yeast extract were added to cultural medium in concentrations of $0.03 \%$ and $0.06 \%$. The medium lacking a nitrogen source was used as a control. It is known that Azotobacters are capable to nitrogen fixation and require Mo ions for this process ${ }^{22,23}$. However, it has been observed that inorganic nitrogen sources enhance Azotobacter growth ${ }^{20}$. These bacteria can metabolize nitrogen in oxidized form as nitrate salts ${ }^{18}$.

It was shown that the minimum of biomass formation in the control (to $2.5 \mathrm{~g} / \mathrm{l}$ on day 3 was observed (Fig. 3). It is know, that bacterium use two enzymatic systems utilizing nitrates: the first in reducing nitrate to nitrite, the second - nitrate to ammonium. In experiments with minimum nitrate content (Fig. $3 \mathrm{~A}$ ), the biomass was at the control level $(2.5 \mathrm{~g} / 1)$. The maximum biomass production was found at $0.05 \%$ nitrate contended media (C: $\mathrm{N}$ ratio $105: 1$; to $5.24 \mathrm{~g} / \mathrm{l}$ ). At increasing the $\mathrm{NaNO}_{3}$ concentration in the medium to $0.06 \%$ the biomass contents was decreased.

It has been shown that the input of the reduced form of nitrogen, $\left(\mathrm{NH}_{4}\right)_{2} \mathrm{SO}_{4}$, into the medium increase the culture growth (Fig. $3 \mathrm{~B}$ ). At concentration $0.04 \%\left(\mathrm{NH}_{4}\right)_{2} \mathrm{SO}_{4}$, in the $\mathrm{CB}$ the biomass content increased to the maximal level - $8.3 \mathrm{~g} / \mathrm{l}$. and higher concentrations did not effected on the biomass contents, because decreasing the medium $\mathrm{pH}$ the bacterium development limited. So, at $0,04 \%$ ammonium sulfate contended media (C: $\mathrm{N}$ ratio 100:1) the optimal bacterium growth was found. 
Nutrient Sources and Alginate Accumulation

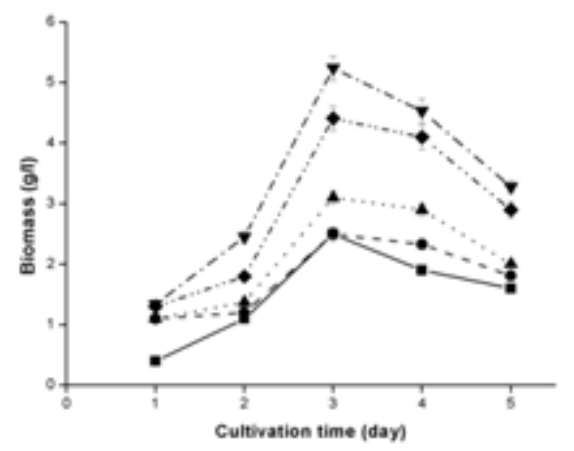

A

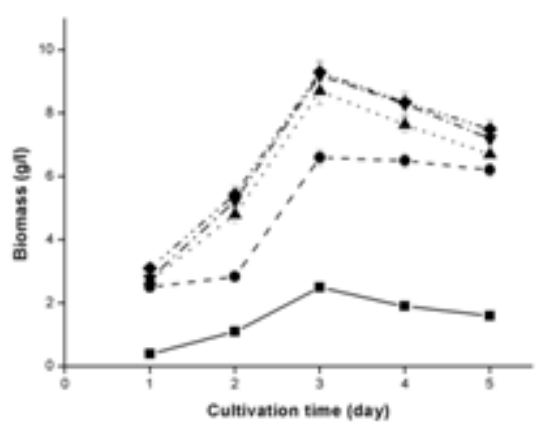

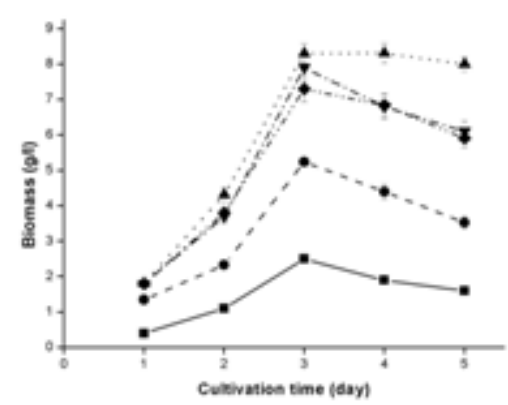

B

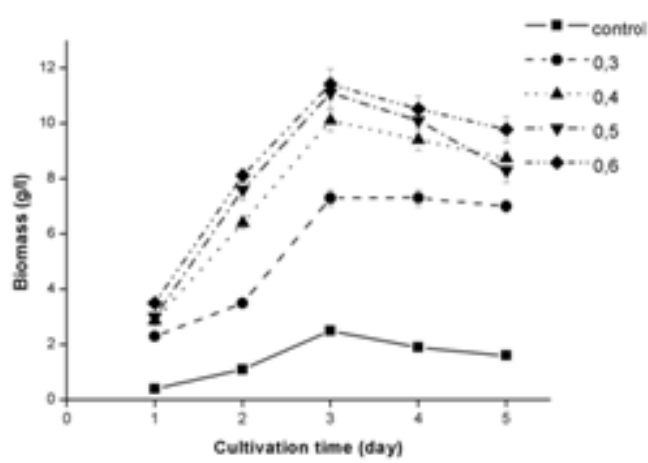

C

Fig. 3. Influence of nitrogen source concentration on the biomass accumulation:

$\mathrm{A}-\mathrm{NaNO}_{3} ; \mathrm{B}-\left(\mathrm{NH}_{4}\right)_{2} \mathrm{SO}_{4} ; \mathrm{C}-$ peptone; $\mathrm{D}$ - yeast extract.

Key: Concentration $(\%)$ : Control $(\boldsymbol{\bullet}), 0.3(\bullet), 0.4(\boldsymbol{\Delta}), 0.5(\boldsymbol{\nabla}), 0.6(\bullet)$

Compare the inorganic forms of nitrogen and organic sources (such as peptone and yeast extract) added to the media, the maximal biomass contents on the medium with peptone (a product of incomplete digestion of proteins) was observed (at peptone concentrations of $0.05-0.06 \%$ (C: $\mathrm{N}$ ratio $100-120: 1$ ) (Fig. $3 \mathrm{C}$ ).

The substitution of the peptone for yeast extract, the growth of the bacterium was increased (Figure $3 \mathrm{D}$ ). As in the case with other nitrogen sources, increasing the yeast extract concentration in the medium stimulated the biomass formation: $0.05 \%$ of yeast extract (C: $N$ ratio 168: 1) increased the biomass up to $11.1 \mathrm{~g} / 1$. Further increase in this nitrogen source concentration to $0.06 \%$ no effected the bacterium growth.

So, it can be found that the maximal growth was observed in a medium containing $0.05-0.06 \%$ yeast extract (carbon / nitrogen ratio 168: 1).

The exopolysaccharide (EPS) formation, as the microorganism growth, is affected by the media composition. We have studied the changes in the amount of the EPS, alginate, depending on the nitrogen source and it concentrations. In all experiments, including the control, alginate biosynthesis was increased during 4 days, which corresponds to the stationary growth phase of the culture. (Figure 4). 


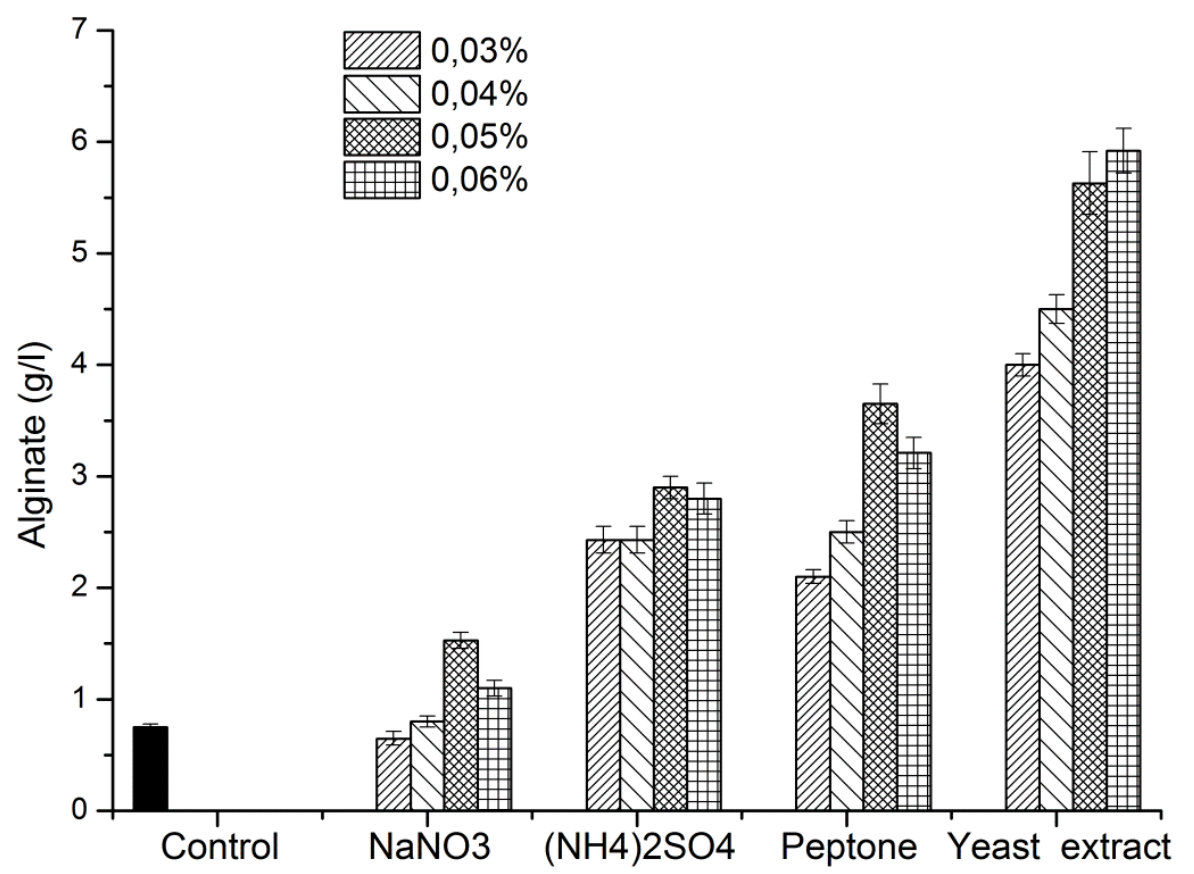

Fig. 4. Influence of the nitrogen source nature and concentration on the alginate biosynthesis (4 days of growth)

Compared to the control, the nitrates stimulated alginate biosynthesis. Addition only $0.05-0.06 \%$ nitrate slightly increased the polysaccharide content in $\mathrm{CB}$ in our experiments as in the literature data ${ }^{18}$. The effectivity of the reduced form of nitrogen $\left(\left(\mathrm{NH}_{4}\right)_{2} \mathrm{SO}_{4}\right)$ contended media was more for alginate biosynthesis than the oxidized form (sodium nitrate), which is apparently due to the more rapid adaptation of the reduced form of nitrogen for the bacterium metabolism. In experiments with sulfate contended media, the highest EPS content was observed at a concentration $0.04 \%$ (carbon: nitrogen ratio 100: 1 and amounted to $3.2 \mathrm{~g} / \mathrm{l}$ )/ In the reported data, it was found the optimal carbon: nitrogen ratio for alginate biosynthesis was in the range of $60-100: 1^{15}$ So, the microorganism cultivation and alginate biosynthesis increased at higher content of the ammonia nitrogen $(0.1-0.2 \%)$ in cultivation medium ${ }^{24}$. When we are using the peptone, the EPS content generally depended on the ammonium sulfate concentration: at $0.05 \%$ peptone (carbon: nitrogen ratio $120: 1$ ) the alginate production was on $13 \%$ higher than with sulfate. The maximum alginate content $(5.63 \mathrm{~g} / \mathrm{l})$ was observed when $0.05 \%$ yeast extract (carbon: nitrogen ratio 168: 1 ) was used.

Tables 1 and 2 show the kinetics of cell growth and alginate production in media with various sources of carbon and nitrogen. It was found that the specific growth rate of biomass production was higher in $4 \%$ glucose contained media $\left(0,297 \mathrm{~h}^{-1}\right)$ as a carbon source and with yeast extract $(0,159 \mathrm{~h}-1$, with $2 \%$ sucrose $)$ as a source of nitrogen. At the same time, the alginate $\mathrm{Y}_{\mathrm{P} / \mathrm{X}}$ in relation to biomass was higher in the experiment with 1.5 - $2 \%$ mannite contained media $(0,77-0,81 \mathrm{~g} / \mathrm{g})$ and the lactose contained media $(0,6-0,65 \mathrm{~g} / \mathrm{g})$ but the biomass from glucose provided the lowest of alginate amount $(0,38-0,42 \mathrm{~g} / \mathrm{g})$. Among the nitrogen sources, the highest value of alginate contents was found at $0,03-0.06 \%$ of yeast extract contained media $(0,48-0.56 \mathrm{~g} / \mathrm{g})$ and $0.03 \%$ ammonium sulfate contained media $(0,55 \mathrm{~g} / \mathrm{g})$.

The biotechnology effect is based on the product EPS was calculated on a unit of substrate $\mathrm{Y}_{\mathrm{P} / \mathrm{s}}$. It was found that the medium with $1 \%$ sucrose contained media made the highest $\mathrm{Y}_{\mathrm{P} / \mathrm{S}}$ ratio $(0.303 \mathrm{~g} / \mathrm{g})$; therefore, over $30 \%$ of the substrate is used to produce the polysaccharide. Increasing the concentration of the substrate up to $4 \%$ contained media, leads courses to a 2 -fold decrease $\mathrm{Yp} / \mathrm{s}$, although the alginate 
Nutrient Sources and Alginate Accumulation

volumes production had increased. Higher amounts of yeast extract in the medium provide the highest biotechnology effect of all the sources of nitrogen contained media.

Table 1. Fermentation parameters of alginate produced of A.vinelandii with different carbon sources

\begin{tabular}{lllll}
\hline Carbon source & Concentration, $\%$ & $\mu, \mathrm{h}^{-1}$ & $\mathrm{Y} / \mathrm{S}, \mathrm{g} / \mathrm{g}$ & $\mathrm{Y} / \mathrm{P}, \mathrm{g} / \mathrm{g}$ \\
\hline Mannitol & 1,5 & $0,045 \pm 0.003$ & $0,16 \pm 0.011$ & $0,774 \pm 0.054$ \\
\cline { 2 - 5 } & 2 & $0,06 \pm 0.004$ & $0,170 \pm 0.052$ & $0,808 \pm 0.06$ \\
\hline Lactose & 4 & $0,78 \pm 0.044$ & $0,038 \pm 0.002$ & $0,3 \pm 0.052$ \\
\cline { 2 - 5 } & 1,5 & $0,09 \pm 0.005$ & $0,233 \pm 0.017$ & $0,648 \pm 0.041$ \\
\cline { 2 - 5 } & 2 & $0,11 \pm 0.009$ & $0,21 \pm 0.014$ & $0,534 \pm 0.033$ \\
\hline Sucrose & 4 & $0,078 \pm 0.005$ & $0,09 \pm 0.006$ & $0,6 \pm 0.041$ \\
\hline Glucose & 2 & $0,153 \pm 0.008$ & $0,303 \pm 0.016$ & $0,454 \pm 0.032$ \\
\cline { 2 - 5 } & 4 & $0,167 \pm 0.01$ & $0,275 \pm 0.02$ & $0,492 \pm 0.032$ \\
\hline & 1,5 & $0,172 \pm 0.009$ & $0,15 \pm 0.009$ & $0,488 \pm 0.029$ \\
\hline & 2 & $0,152 \pm 0.01$ & $0,271 \pm 0.019$ & $0,383 \pm 0.022$ \\
\hline
\end{tabular}

Table 2. Fermentation parameters of alginate produced of A.vinelandii with different carbon sources

$\begin{array}{lllll}\text { Nitrogen source } & \begin{array}{l}\text { Concentration, } \\ \%\end{array} & \mu, h^{-1} & Y_{P / S}, g / g & Y_{P / X}, g / g \\ \end{array}$

\begin{tabular}{lcccc}
\hline $\mathrm{NaNO}_{3}$ & 0,03 & $0,035 \pm 0.002$ & $0,033 \pm 0.002$ & $0,279 \pm 0.02$ \\
\cline { 2 - 5 } & 0,04 & $0,043 \pm 0.003$ & $0,04 \pm 0.003$ & $0,276 \pm 0.019$ \\
\cline { 2 - 5 } & 0,05 & $0,073 \pm 0.005$ & $0,077 \pm 0.005$ & $0,338 \pm 0.022$ \\
\hline$\left(\mathrm{NH}_{4}\right)_{2} \mathrm{SO}_{4}$ & 0,06 & $0,061 \pm 0.004$ & $0,055 \pm 0.003$ & $0,268 \pm 0.018$ \\
\cline { 2 - 5 } & 0,03 & $0,073 \pm 0.005$ & $0,122 \pm 0.009$ & $0,552 \pm 0.044$ \\
\cline { 2 - 5 } & 0,05 & $0,115 \pm 0.008$ & $0,13 \pm 0.008$ & $0,385 \pm 0.025$ \\
\cline { 2 - 5 } & 0,06 & $0,11 \pm 0.009$ & $0,145 \pm 0.010$ & $0,426 \pm 0.035$ \\
\hline Peptone & 0,03 & $0,101 \pm 0.008$ & $0,14 \pm 0.009$ & $0,409 \pm 0.03$ \\
\cline { 2 - 5 } & 0,04 & $0,092 \pm 0.006$ & $0,105 \pm 0.007$ & $0,323 \pm 0.021$ \\
\cline { 2 - 4 } & 0,05 & $0,121 \pm 0.009$ & $0,125 \pm 0.008$ & $0,327 \pm 0.021$ \\
\hline Yeast extract & 0,06 & $0,128 \pm 0.008$ & $0,183 \pm 0.013$ & $0,44 \pm 0.03$ \\
\hline
\end{tabular}




\begin{tabular}{ccccc}
\hline 0,04 & $0,14 \pm 0.009$ & $0,225 \pm 0.017$ & $0,478 \pm 0.031$ \\
\cline { 2 - 4 } & 0,05 & $0,154 \pm 0.01$ & $0,282 \pm 0.021$ & $0,557 \pm 0.04$ \\
\hline 0,06 & $0,159 \pm 0.011$ & $0,296 \pm 0.022$ & $0,563 \pm 0.041$ \\
\hline
\end{tabular}

One of the major tasks of any microbiological production is to reduce the product costs. Therefore, the next step involved $A$. vinelandii cultivation in molasses containing medium. Molasses is a by-product of sugar beet production, characterized by a relatively high content of sucrose, which is difficult to extract in the technological process. Besides sucrose molasses is rich in trace elements, vitamins, nitrogen. It therefore can serve as a cheap raw material for the culture media preparation. The results of $A$. vinelandii cultivation on molasses medium showed that the microorganism grows well and the alginate content in $\mathrm{CB}$ as compared for modified M22 medium increases 2.7-fold and reaches $16.6 \mathrm{~g} / 1$ on 3 day of cultivation.

Currently, one of the promising biotechnological areas is in the production of biocomposite materials based on the polysaccharides that are used as a biological binder ${ }^{4}$. In this investigation, we used the alginate as a part of the CB for the wood chipboards production. In the conventional technological scheme, urea-formaldehyde, phenol-formaldehyde are used and it is toxic for people and animals. Therefore, the replacement of the synthetic binders by environmentally friendly bio-binders remains an urgent issue. For this purpose, in our work the sawdust was mixed with a culture broth containing the alginate. The mass was dried to a moisture content of $6-8 \%$ for the samples compression in a molding hydraulic press. It was shown that the chemical binders replacement with $\mathrm{CB}$ alginate, change the bioplastics parameters: the samples tensile strength during the pressing for $20 \mathrm{~min}$ amounted to $14.4 \mathrm{MPa}$ (Table 3) that corresponds to with EN 312:2003 «Particle boards - Specifications», NEQ, the samples water absorption and the samples swelling had overstated values - to 22.6 and $28.6 \%$, respectively.

Table 3. Physical and mechanical properties of biocomposite materials

\begin{tabular}{ll}
\hline Indicator & Biocomposite based on CB with 1\% paraffin \\
\hline Tensile strength, $\mathrm{MPa}$ & $14.4 \pm 0.7$ \\
\hline Density, kg / $\mathrm{m}^{3}$ & $1185 \pm 59$ \\
\hline Water absorption, \% & $22.6 \pm 1.1$ \\
\hline Swelling in thickness, \% & $28.6 \pm 1.4$ \\
\hline
\end{tabular}

\section{CONCLUSIONS}

In this study was found, that the biomass production and the alginate biosynthesis are depended not only a type of carbon source but also by its concentration: the maximal alginate contents were observed during cultivation in a medium containing sucrose. It was shown that using $A$. vinelandii D-05 bacterium for the alginate biosynthesis requires additional the nitrogen source, and the organic forms are better consumed. The highest level of the polysaccharide productions observed in the $0.05 \%$ of yeast extract (carbon / nitrogen ratio 168:1) contained media. It was shown that the bacterium is able to grow on molasses medium providing the alginate yield of $16.6 \mathrm{~g}$ / 1. The culture broth obtained can be used as a biological binder for the production of the ecological biocomposite materials.

\section{ACKNOWLEDGMENTS}


Nutrient Sources and Alginate Accumulation

This work was supported by the project part of the state assignment (Russia) [15.684.2014K] from 17.07.2014.

\section{REFERENCES}

1 Shih I-L. Microbial exopolysaccharides for biomedical applications. Mini-Reviews in Medicinal Chemistry. 2010; 10(14): 1345-1355.

2 Mahajan HS, Nerkar PP. Gellan gum: A versatile excipient. Pharma Times. 2013; 45(3): 8384.

3 Freitas F, Alves VD, Reis MA. Advances in bacterial exopolysaccharides: from production to biotechnological applications. Inc. J. Appl. Polym. Sci. 2011; 29(8): 388 - 398.

4 Revin VV, Shutova VV, Kadimaliev DA, Atykyan NA, Vedyashkina TA, Ivinkina TI. Theoretical and applied fundamentals of biocomposite materials obtaining using biological binders (in Russian). Saransk: Publishing House of Mordovia State University; 2010.

5 Chowdhury SR, Manna S, Saha P, Basak RK, Sen R, Roy D, Adhikari B. Composition analysis and material characterization of an emulsifying extracellular polysaccharide (EPS) produced by Bacillus megaterium RB-05: A hydrodynamic sediment-attached isolate of freshwater origin. J. Appl. Microbiol. 2011; 111(6): 1381-1393.

6 Mabrouk MEM, El-Ahwany AMD, Beliah MMB, Sabry SA. Xanthan production by a novel mutant strain of Xanthomonas campestris: Application of statistical design for optimization of process parameters. Life Sci. J. 2013; 10(6): 1660-1667.

7 Sabra W, Zeng A-P, Deckwer W-D. Bacterial alginate: physiology, product quality and process aspects. Appl. Microbiol. Biotechnol. 2001; 56: 315-325.

8 Augst AD, Kong HJ, Mooney DJ. Alginate hydrogels as biomaterials. Macromol. Biosci. 2006; 6(8): 623-633.

9 Gauri SS, Mandal SM, Pati BR. Impact of Azotobacter exopolysaccharides on sustainable agriculture. Appl. Microbiol. Biotechnol. 2012; 95(2): 331-338.

10 Hay ID, Rehman ZU, Moradali MF, Wang Y, Rehm BHA. Microbial alginate production, modification and its applications. Microb. Biotechnol. 2013; 6(6): 637-650.

11 Zhang Yu, ZhengW, Gu J-F, Ni J, Wang L, Tang Z-X et al. Soy Protein Isolate-Alginate Microspheres for Encapsulation of Enterococcus faecalis HZNU P2. Braz. arch. biol. technol. 2015; 58(5): 805-811.

12 Combie J. Natural polymer with adhesive properties produced by bacteria. Adhesives and Sealants Industry. 2003; 10(5): 26-27.

13 Revin VV, Shutova VV. Adhesives on the base of modified Leuconostoc mesenteroides cultural fluid. Journal of Biotechnology. 2015; 208(Supplement): S116-S116.

14 Revin VV, Novokuptsev NV, Kadimaliev DA. Preparation of Biocomposites using Sawdust and Lignosulfonate with a Culture Liquid of Levan Producer Azotobacter vinelandii as a Bonding Agent. BioResources. 2016; 11(2): 3244-3258.

15 Revin VV, Shutova VV, Novokuptsev NV. Biocomposite materials from lignocellulose raw materials and levan produced by Azotobacter vinelandii. Journal of Biotechnology. 2016; 231 (Supplement): S8.

16 Tanaka Y, Hayashi T, Yamaoka N, Takada Y. Cloning and expression of the isocitrate lyase gene from a nitrogen-fixing bacterium, Azotobacter vinelandii, and functional analysis of the enzyme by site-directed mutagenesis. Biosci. Biotechnol. Biochem. 2012; 76(1): 78-83.

17 Gauri SS, Mandal SM, Mondal KC, Dey S, Pati BR. Enhanced production and partial characterization of an extracellular polysaccharide from newly isolated Azotobacter sp. SSB81. Bioresource Technol. 2009. 100: 4240-4243.

18 Vermani M.V., Kelkar S.M., Kamat M.Y. Studies in polysaccharide production and growth of Azotobacter vinelandii MTCC 2459, a plant rhizosphere isolate. Lett. Appl. Microbiol. 1997; 24: 379-383.

19 Clementi F, Fantozzi P, Mancini F, Moresi M. Optimal conditions for alginate production by Azotobacter vinelandii. Enzyme Microb. Tech. 1995; 17(11): 983-988. 
20 Galal GF, Ouda SM. Production of alginate by different isolates of Azotobacter species. Life Sci. J. 2014; 11(9): 29-38 ().

21 Fuchs C, Kroge A. Biology of the prokaryotes, In: Lengeler J, Drews G, Schlegel H, editors. Georg Thieme Verlag; 1999.

22 Howard JB, Rees DC. How many metals does it take to fix $\mathrm{N}_{2}$ ? A mechanistic overview of biological nitrogen fixation. P. Natl. Acad. Sci. USA. 2006; 103(46): $17088-17093$.

$23 \mathrm{Hu}$ Y, Ribbe MW. Biosynthesis of the iron-molybdenum cofactor of nitrogenase. J. Biol. Chem. 2013; 288(19): 13173-13177.

24 Parente E, Crudele MA, Aquino M, Clementi F. Alginate production by Azotobacter vinelandii DSM 576 in batch fermentation. J. Ind. Microbiol. Biotech. 1998; 20: 171-176.

Received: February 03, 2016; Accepted: July 14, 2016 